\title{
Diyabetik ketoasidozun nadir bir komplikasyonu: Akut özofageal nekroz
}

\author{
A rare complication of diabetic ketoacidosis: Acute esophageal necrosis
}

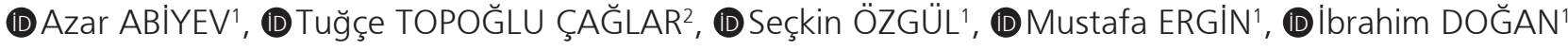 \\ Gazi Üniversitesi Tıp Fakültesi, ${ }^{1}$ Gastroenteroloji Bilim Dalı, ${ }^{2}$ ç Hastalıkları Anabilim Dalı, Ankara
}

\begin{abstract}
Akut özofagus nekrozu distal özofagusu çevresel olarak tutan ve mukozada siyah nekrotik görünüme neden olan nadir görülen bir sendromdur. Prezentasyon şekli vakaların çoğunda üst gastrointestinal kanamadır. Diyabet, diyabetik ketoasidoz ve kardiyovasküler hastalıklar hastalığın risk faktörleri arasında yer alır. Biz burada diyabetik ketoasidoz komplikasyonu olarak gelişen akut özofagus nekrozu olgusundan bahsedeceğiz.
\end{abstract}

Anahtar kelimeler: Üst gastrointestinal kanama, akut özofageal nekroz, diyabetik ketoasidoz

\section{GíRiş}

Gurvits sendromu, "siyah özofagus" veya akut nekrotizan özofajit olarak da bilinen akut özofagus nekroz (AÖN) üst gastrointestinal sistem (GIS) kanamasının nadir bir nedenidir. "Siyah özofagus" terminolojisi, akut nekrotizan özofajitin tipik endoskopik görünümünden kaynaklanmaktadır. Bu hastalıkta özofagus distalinde siyah renkli mukozadan alınan biyopsiler de nekrotik lezyonları doğrulamaktadır (1). Akut özofagus nekrozu risk faktörleri arasında erkek cinsiyet, ileri yaş (genellikle yaşamın altıncı on ylında), paraözofageal herni, travma, diyabetes mellitus (DM), diyabetik ketoasidoz (DKA), hipertansiyon, kardiyovasküler hastalıklar, periferik arter hastalığı gibi komorbiditelerin varlığı yer alır (2). Bu yazıda diyabetik ketoasidoz komplikasyonu olarak gelişen AÖN olgusundan bahsedeceğiz.

\section{OLGU SUNUMU}

Seksen sekiz yaşında kadın hasta kanlı kusma ve siyah dışkılama şikayeti ile acil servise başvurdu. Hastanın öyküsünde DM, hipertansiyon ve koroner arter hastalığı gibi kronik hastalıkları olduğu öğrenildi, daha önce geçirilmiş gastrointestinal kanama öyküsü yoktu. Fizik muayenede batında hassasiyet saptandı ve rektal tuşe melena ile uyumlu idi. Vitallerinde ateş $36.4{ }^{\circ} \mathrm{C}$, kan basıncı 125/70 $\mathrm{mmHg}$, kalp atım hızı 95 atım/dakika, solunum hızı 22/ dakika ve oksijen satürasyonu \%97 idi. Yapılan laboratuvar tetkiklerinde kan üre azotu: 49 mg/dl, kreatinin: 1.58

\footnotetext{
Iletişim: Azar ABIYEV

Gazi Üniversitesi Tıp Fakültesi, Gastroenteroloji Bölümü

Beştepe, Ankara

Tel: +9031220258 19 • E-mail: drazerabiyev@gmail.com
}

Acute esophageal necrosis is a rare syndrome involving the distal esophagus peripherally and causing a black necrotic appearance in the mucosa. The clinical presentation is upper gastrointestinal bleeding in most cases. Diabetes, diabetic ketoacidosis and cardiovascular diseases are among the risk factors for the disease. Here, we present a case of acute esophageal necrosis as a complication of diabetic ketoacidosis.

Keywords: Upper gastrointestinal bleeding, acute esophageal necrosis, diabetic ketoacidosis

$\mathrm{mg} / \mathrm{dl}$, sodyum: $122 \mathrm{mmol} / \mathrm{L}$, aspartat aminotransferaz: $30 \mathrm{U} / \mathrm{L}$, alanin amino transferaz: $12 \mathrm{U} / \mathrm{L}$, albümin $3.2 \mathrm{~g} /$ dl, hemoglobin: $11.3 \mathrm{~g} / \mathrm{dl}$, platelet: $311000 / \mathrm{ul}$, lökosit: 12560/ul, kan şekeri: 794 mg/dl, venöz kan gazında pH: 7.162, parsiyel arteriyel karbondioksit basıncl: 26.1 $\mathrm{mmHg}$, bikarbonat: $10.8 \mathrm{mEq} / \mathrm{L}$, idrar tetkikinde keton $(++)$ olarak sonuçlandı. Hasta DKA tanısı ile hastaneye yatıııldı, kristalloid sıvı ve insülin infüzyonu başlandı. Üst Gis kanama ön tanısı ile acil özofagogastroduodenoskopi (ÖGD) yapıldı. ÖGD'de, kesici dişlerden itibaren 23. cm'den 27. cm'e kadar lümeni çepeçevre saran, üzeri siyah nekrotik doku ile kaplı alan izlendi (Resim 1). Hastada akut özofagus nekrozu düşünüldü. DKA için verilen tedaviye ek olarak pantoprazol infüzyonu, 6*1 antasid tedavisi (aljinik asit) başlandı, oral alımı kısıtlandı ve total parenteral beslenmeye geçildi. Takiplerinde hastanın hemoglobin düşüşü ve melenası olmadı, kan şekeri regülasyonu sağlandı, asidozu geriledi ve idrarda keton negatifleşti. Hastaya bazal ve bolus insülin tedavisi başlandı. İlk başvurudan 1 hafta sonra yapılan kontrol ÖGD'de özofagus distalindeki 4 cm'lik segmentte nekrotik görünümün gerilediği görüldü ve özofagogastrik bileşkeye kadar uzanan ve lümenin \%70'ni saran erozyon alanları izlendi (Resim 1). Hastanın oral alımı sağlandı ve genel durumu iyi olan hasta taburcu edildi. Hastanın kendisinden bilgilendirilmiş onam formu alınmıştır. 


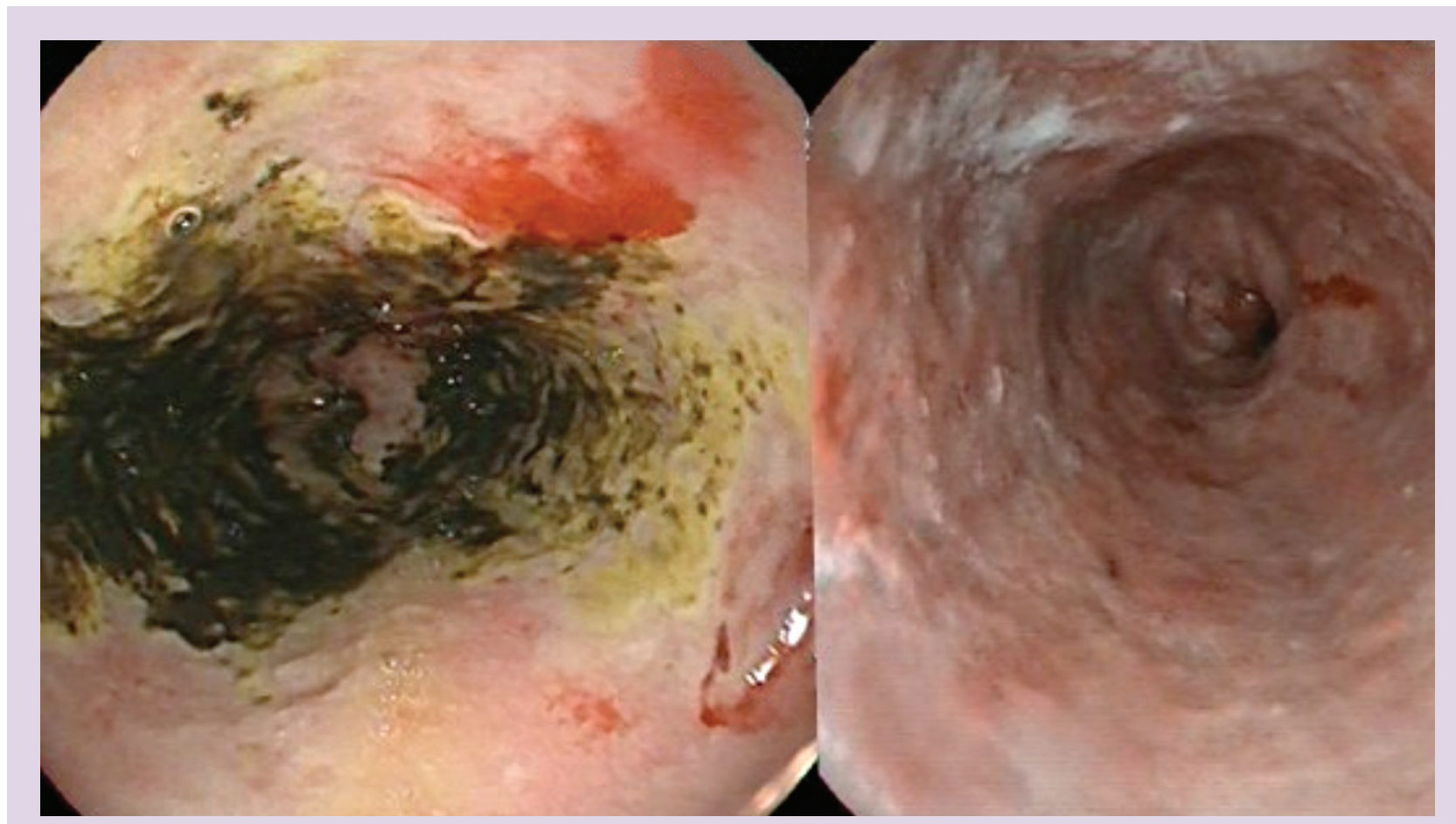

Resim 1. ÖGD'de akut özofagus nekrozu: tedaviden önce ve 1 hafta sonra

\section{TARTIŞMA}

Akut özofagus nekrozu (AÖN), ilk kez 1990 yılında Goldenberg ve arkadaşları tarafından tanımlanmıştır (3). AÖN otopsi serilerinde \%0.2'ye kadar, retrospektif bir çalışmada ise \%0.001 - 0.2 arasında değişen bir klinik insidansla bildirilmiştir $(4,5)$. Ortalama tanı yaşı 67'dir, erkeklerde ve kritik hastalığı olan ve birden fazla komorbiditesi olan hastalarda daha sık görülür (2).

Akut özofagus nekrozunda üst GiS kanama hastane yatışı gerektiren en yaygın klinik tablodur. Kardiyovasküler olay veya herhangi bir etlyolojiye bağlı şok tablosunda olan hastalarda en yaygın prezentasyon şekli üst gastrointestinal kanamadır. Hastaların çoğunda hematemez (\%66), hipotansiyon/senkop (\%36), melena (\%33), akut karın ağrısı (\%28), ardından ateş/enfeksiyon (\%13) ve disfaji (\%12) görülmektedir (6).

Bu klinik varlığın patogenezini açıklamak için birçok teori öne sürülmüştür. Yakın tarihli bir vaka serisinde, hastaların yaklaşık \%90'nın hiperglisemisi olduğu ortaya konmuştur (7). Bizim vakamızda da olduğu gibi birkaç çaış̧mada DKA'nın AÖN ile ilişkili olduğu bildirilmiştir (8). Artmış kan glukoz konsantrasyonu nedeniyle görülen geçici non-obstrüktif gastropati, AÖN patogenezinde rol oynayabilir. Kötü beslenme durumu ile birlikte vasküler yetersizlik, hemodinamik instabilite ve hiperglisemi, kan akışının azalmasına, mukozal hasara, koruyucu bariyerle- rin ve onarım mekanizmalarının bozulmasına yol açar (9). Bizim vakamızda da görüldüğü gibi uzun süredir devam eden DM varlığı, hastayı ateroskleroz gelişimine ve artan iskemi riskine yatkın hale getirir.

AÖN için spesifik bir tedavi yoktur. Tedavinin temel dayanağı, altta yatan akut tablonun düzeltilmesi ve destekleyici bakımdan oluşur. Hemodinamik olarak stabil hastalarda bile, vasküler perfüzyonu optimize etmek ve iskemiye ikincil hasarı en aza indirmek için intravenöz sıvı tedavisi ile sistemik resüsitasyon önerilir. Diğer bir önemli ölçü, özofagus mukozasını agresif asit reflüden korumak için antiasit tedavinin uygulanmasıdır. Agresif intravenöz proton pompası inhibitörü tedavisi, klinik durumda bir iyileşme olana kadar uygulanmalıdır (10). AÖN yaşamı tehdit eden ciddi bir durum olmasına rağmen, uygun tedavi ile hastaların çoğunda kısa sürede iyileşme sağlanabilir.

Sonuç olarak, diyabetik ketoasidoz ve kardiyovasküler komorbiditesi olan hastalarda üst gastrointestinal kanama nedeni olarak akut özofagus nekrozu akılda tutulmalıdır. DKA'nın hızlı yönetimi ve yeterli destekleyici bakım, akut özofagus nekrozunun düzelmesine neden olabilir ve hayat kurtarıcı olabilir.

Çıkar Çatışması: Yazarlar herhangi bir çıkar çatışması olmadığını beyan ederler. Ayrıca bu çalışmada herhangi bir kişi, kurum veya kuruluştan finansal destek alınmamıştır. 


\section{KAYNAKLAR}

1. Choksi V, Dave K, Cantave R, et al. "Black Esophagus" or Gurvits Syndrome: A Rare Complication of Diabetic Ketoacidosis. Case Rep Gastrointest Med 2017;2017:4815752.

2. Day A, Sayegh M. Acute oesophageal necrosis: a case report and review of the literature. Int J Surg 2010;8:6-14.

3. Goldenberg SP, Wain SL, Marignani P. Acute necrotizing esophagitis. Gastroenterology 1990;98:493-6.

4. Etienne JP, Roge J, Delavierre P, Veyssier P. [Esophageal necrosis of vascular origin]. Sem Hop 1969;45:1599-606.

5. Augusto F, Fernandes $V$, Cremers MI, et al. Acute necrotizing esophagitis: a large retrospective case series. Endoscopy 2004;36:411-5.

6. Abdullah HM, Ullah W, Abdallah $\mathrm{M}$, et al. Clinical presentations, management, and outcomes of acute esophageal necrosis: a systemic review. Expert Rev Gastroenterol Hepatol 2019;13:507-14.
7. Gurvits GE, Cherian K, Shami MN, et al. Black esophagus: new insights and multicenter international experience in 2014. Dig Dis Sci 2015;60:444-53.

8. Im JH, Kim MS, Lee SY, et al. A case of acute esophageal necrosis in a patient with diabetic ketoacidosis. Korean J Med 2012;83:11721.

9. Ben Soussan E, Savoye G, Hochain P, et al. Acute esophageal necrosis: a 1-year prospective study. Gastrointest Endosc 2002;56:213-7.

10. Dias E, Santos-Antunes J, Macedo G. Diagnosis and management of acute esophageal necrosis. Ann Gastroenterol 2019;32:529-40. 